\title{
Recent Advances on the Role of G Protein-Coupled Receptors in Hypoxia-Mediated Signaling
}

\author{
Rosamaria Lappano, ${ }^{1}$ Damiano Rigiracciolo, ${ }^{1}$ Paola De Marco, ${ }^{1}$ Silvia Avino, ${ }^{1}$ Anna Rita Cappello, ${ }^{1}$ \\ Camillo Rosano, ${ }^{2}$ Marcello Maggiolini, ${ }^{1,3}$ and Ernestina Marianna De Francesco ${ }^{1}$
}

Received 1 October 2015; accepted 28 January 2016; published online 10 February 2016

Abstract. G protein-coupled receptors (GPCRs) are cell surface proteins mainly involved in signal
transmission; however, they play a role also in several pathophysiological conditions. Chemically
heterogeneous molecules like peptides, hormones, lipids, and neurotransmitters activate second
messengers and induce several biological responses by binding to these seven transmembrane receptors,
which are coupled to heterotrimeric G proteins. Recently, additional molecular mechanisms have been
involved in GPCR-mediated signaling, leading to an intricate network of transduction pathways. In this
regard, it should be mentioned that diverse GPCR family members contribute to the adaptive cell
responses to low oxygen tension, which is a distinguishing feature of several illnesses like neoplastic and
cardiovascular diseases. For instance, the G protein estrogen receptor, namely G protein estrogen
receptor (GPER)/GPR30, has been shown to contribute to relevant biological effects induced by hypoxia
via the hypoxia-inducible factor (HIF)-1 1 in diverse cell contexts, including cancer. Likewise, GPER has
been found to modulate the biological outcome of hypoxic/ischemic stress in both cardiovascular and
central nervous systems. Here, we describe the role exerted by GPCR-mediated signaling in low oxygen
conditions, discussing, in particular, the involvement of GPER by a hypoxic microenvironment.

KEYWORDS: angiogenesis; GPCRs; GPER; hypoxia; signal transduction.

\section{INTRODUCTION}

G protein-coupled receptors (GPCRs) are seven transmembrane-spanning receptors that regulate many cellular functions upon ligand activation (1). The biological responses mediated by GPCRs involve the recruitment of proteins prompting the receptor internalization and desensitization, like arrestins and GPCR kinases (GRKs) as well as membrane-bound partners, namely heterotrimeric $\mathrm{G}$ proteins $(1,2)$. In the inactive state, $G$ proteins consist of a $G \beta \gamma$ monomer which maintains a high affinity for a guanine diphosphate (GDP)-bound G $\alpha$ subunit $(1,2)$. On the basis of the sequence identity, four subtypes of $G \alpha$ subunit $(G \alpha s, G \alpha i$, $\mathrm{G} \alpha \mathrm{q}$, and $\mathrm{G} \alpha 12$ ) have been extensively characterized $(1,2)$. Ligand binding promotes conformational modifications that result in the exchange of GDP for GTP on the G $\alpha$ subunit, leading to a decreased affinity of $G \alpha$ for the $G \beta \gamma$ subunit. The dissociation of the heterotrimer allows that both GTP-

\footnotetext{
${ }^{1}$ Department of Pharmacy, Health and Nutritional Sciences, University of Calabria, Via Bucci, 87036, Rende, CS, Italy.

${ }^{2}$ UOS Proteomics IRCCS AOU San Martino-IST National Institute for Cancer Research, Largo R. Benzi 10, 16132, Genoa, Italy.

${ }^{3}$ To whom correspondence should be addressed. (e-mail: marcellomaggiolini@yahoo.it; marcello.maggiolini@unical.it)
}

bound $G \alpha$ and free $G \beta \gamma$ activate numerous transduction pathways like mitogen-activated protein kinase (MAPK), phosphatidylinositol 3-kinase (PI3-K), small GTP-binding proteins (Ras and Rho GTPases), and other mediators that contribute to various physiopathological responses $(1,2)$. For instance, an aberrant expression of GPCRs and/or their activation have been associated to several types of tumors $(3,4)$. Consequently, the pharmacological manipulation of certain GPCR-mediated signaling may represent a promising anti-cancer strategy $(3,4)$. As demonstrated for many GPCRs $(3,4)$, the $G$ protein estrogen receptor (GPER, also known as GPR30) may trigger oncogenic signaling $(5,6)$. GPER binds to estrogens, phyto- and xenoestrogens, and also estrogen receptor (ER) antagonists that may act as GPER agonists (7-12). GPER mediates the activation of a network of transduction pathways; however, the actual role elicited by GPER in tumorigenesis is still controversial. Previous studies have shown that GPER may induce cell cycle arrest and inhibition of cancer cell growth (13-16). Nevertheless, other in vitro and in vivo studies have revealed that GPER triggers cancer cell migration and proliferation $(5,17)$. In addition, GPER expression was associated to inflammatory breast tumor (18), was found reduced during breast cancer tumorigenesis (19), and was related to a poor relapse-free survival in breast cancer patients treated with tamoxifen (20). The lack of GPER in the plasma membrane was linked to a 
favorable prognosis in breast cancer (21), whereas its expression was associated with aggressive features of breast, endometrial, and ovarian tumors (22-24). In this context, we have demonstrated that GPER is upregulated by EGF, insulin-like growth factor (IGF)-I, insulin, and a main factor contributing to tumor aggressiveness like hypoxia (25-31). A low oxygen tension characterizes the growth of solid tumors, where it promotes adaptive responses like anaerobic glycolysis, reduction of macromolecule synthesis, and angiogenesis (32). In addition, hypoxia is critical for the pathogenesis of heart disease and stroke, the major causes of human mortality (33). The effects of hypoxia are mainly mediated by hypoxiainducible factor (HIF) family members, which orchestrate the complex responses to low oxygen tension (34). In particular, HIF- $1 \alpha$ regulates the expression of several pro-angiogenic factors involved in tumor angiogenesis progression $(34,35)$. Many signaling cascades are engaged by hypoxia toward HIF$1 \alpha$ activation such as receptor tyrosine kinases (RTKs) and GPCRs $(30,31,36)$. Here, we discuss the involvement of certain GPCRs, including GPER, in hypoxia-mediated signaling toward cancer development and cardiovascular diseases.

\section{GPCR INVOLVEMENT IN HYPOXIA-MEDIATED SIGNALING}

A low oxygen tension characterizes relevant pathophysiological conditions like cancer and cardiovascular diseases (32-34). Multiple mechanisms for oxygen sensing have been developed and conserved in both prokaryotic and eukaryotic organisms (32-34). In particular, HIF-1 acts as a master regulator of the adaptive cell response to limited oxygen availability mainly by activating the transcription of genes that regulate physiological processes as glycolysis, survival, and angiogenesis (34-37). HIF-1 is a heterodimer of two helix-loop-helix-PAS proteins, namely HIF- $1 \alpha$ and HIF-1 $\beta$ or ARNT (38). Upon hypoxia, HIF- $1 \alpha$ and HIF-1 $\beta$ dimerize and bind to the hypoxia-responsive elements (HREs) located within the promoter region of target genes (38). Several factors contribute to HIF- $1 \alpha$-mediated action in hypoxic conditions, including diverse GPCRs $(30,39)$. For instance, GPR41 was shown to be a hypoxia-induced receptor that drives p53-dependent apoptosis in rat cardiomyocytes subjected to ischemia and reoxygenation injury (40) whereas GPR22 was involved in cardioprotection as its ablation increased the susceptibility to functional decompensation following hemodynamic stress (41). The adrenergic signaling axis, consisting of catecholamines and their adrenergic receptors, has been included among GPCRs that play a primary role in oxygen-related diseases like hypertension, cardiac hypertrophy, and heart failure (42). Moreover, the adrenoreceptors have been shown to functionally interact with opioid receptors (43), which elicit protective actions in response to pre- and post-conditioning stimuli upon cardiac and cerebral damages $(44,45)$. It is worth noting that certain ligand-activated GPCRs induce HIF-1 expression and function (46-48), thus mimicking hypoxic conditions. For instance, the recruitment of transcription factors to the promoter sequence of HIF-1 as well as the stabilization of HIF-1 protein levels may occur upon activation of GPCRs by endothelin-1 (ET-1), $\beta$-adrenoceptor agonists, and lysophosphatidic acid (46-48).

\section{GPCR INVOLVEMENT IN TUMOR ANGIOGENESIS UPON HYPOXIA}

Tumor microenvironment is often characterized by hypoxia, which is a distinguishing feature of an aggressive cancer phenotype and disease recurrence (32). The metabolic changes occurring in rapidly growing cells, the increasing diffusion distances between the blood vessels and certain tumor areas, and the compressive action elicited by the expanding mass on local blood vessels may cumulatively account for low intra-tumor oxygenation (32). The effects of hypoxia on the malignant progression are mediated by complex mechanisms that allow tumor cells to survive and/ or escape their oxygen-deficient environment (32,34). Moreover, the adaptive responses to hypoxic stress in the tumor microenvironment trigger the formation of new blood vessels stimulated by pro-angiogenic factors $(35,37)$. Along with the activation of endothelial cells (ECs) and the subsequent degradation of the basement membrane, the angiogenic response leads to the migration and proliferation of ECs, which then form tubes generating new blood vessels (49). Moreover, tumor angiogenesis prompts cancer cells to grow, evade the host surveillance, form the pre-metastatic niche, and invade distant sites (49); hence, the molecular players driving this complex process are intensively investigated toward effective anti-tumor strategies (49). To date, the major growth factors involved in the formation of blood vessels are members of the vascular endothelial growth factor (VEGF) family (50). It includes placental growth factor (PlGF), VEGF-A VEGF-B, VEGF-C, VEGF-D, and VEGF-E, which bind to the tyrosine kinase receptors, namely $\mathrm{VEGF}$ receptor (VEGFR)-1, VEGFR-2, and VEGFR-3 (50). VEGF-A mainly mediates new blood vessel formation within the tumor mass as its binding to VEGFR-2 promotes EC proliferation, migration, and vascular permeability (50). Hormones, cytokines, and growth factors have been shown to boost VEGFdependent tumor angiogenesis; however, hypoxia represents the primary stimulus for VEGF production and release in the tumor microenvironment (50). Diverse members of the GPCR family are involved in the angiogenic action induced by thrombin, prostaglandins, lysophosphatidic acid, chemokines, and sphingosine 1-phosphate in different pathophysiological conditions, suggesting that certain GPCRs contribute to the development of blood vessels (51-54). In addition, the heterotrimeric $\mathrm{G}$ proteins $\mathrm{G} \alpha \mathrm{q}$ and $\mathrm{G} \alpha 11$ may contribute to angiogenic responses by interacting with VEGFR-2 (55) and the G protein-coupled receptor kinase 2 (GRK2) has recently emerged as an integrative node toward the development of cancer-associated vascularization (56). In the tumor microenvironment, chemokines and their receptors elicit relevant paracrine actions, as suggested by the ability of CCL2, CCL5, and CXCL8/IL-8 to recruit within the tumor mass leukocytes and macrophages, which release VEGF and other angiogenic factors (57). Furthermore, cytokines may stimulate the production of prostaglandin E2 (PGE2), which increases the secretion of VEGF, CXCL8, and CXCL5 by tumor and stromal cells (57). Overall, these data suggest that GPCR-mediated signaling may modulate the angiogenic 
process together with the VEGF/VEGFR axis. Further corroborating these observations, the anti-tumor activity exhibited by several GPCR antagonists has been correlated with their anti-angiogenic properties and anti-proliferative effects (58). Among the GPCRs contributing to the formation of new blood vessels in hypoxic conditions, the chemokine receptor CXCR4 that binds to the stromal cell-derived factor1 (SDF-1)/CXCL12 has been shown to stimulate tumor outgrowth and metastasis as well as angiogenesis upon hypoxia (59). The angiogenic factor named adrenomedullin (ADM) signals through the calcitonin receptor-like receptor (CRLR), which is a GPCR expressed in several tumors like the high-vascular clear renal cell carcinoma (RCC) $(60,61)$. A functional consensus HRE was identified within the promoter region of the human CRLR gene, thus corroborating the role of CRLR in the formation of new blood vessels upon hypoxic conditions $(60,61)$. Among the vasoactive pro-angiogenic molecules, ET-1 and the cognate receptors (ETRs) are aberrantly activated in diverse malignancies and regulated by low oxygen tension through HIF-1 $\alpha$ (62). In this regard, HIF-1 $\alpha /$ VEGF signaling has been considered as a downstream transduction pathway activated by the ET-1 axis (62). For instance, in human chondrosarcoma cells, ET-1 promoted the expression of VEGF, angiogenesis, and cell migration by activating integrin-linked kinase (ILK), Akt, and HIF-1 $\alpha$-mediated signaling cascades (63). In ovarian carcinoma, in both normoxic and hypoxic conditions, ET-1 induced the transcription and accumulation of HIF- $1 \alpha$ and the upregulation of VEGF, suggesting that ET-1 action may be linked to hypoxia and HIF-1 $\alpha$ dependent angiogenesis (64). In our recent study (65), we also found that ET-1 may trigger GPER expression and function leading to angiogenic responses. Recently, the adrenergic system has been shown to boost tumor angiogenesis and aggressive features through the upregulation of diverse angiogenic factors like VEGF, IL-6, IL-8, matrix metalloproteinase (MMP)-2, and MMP-9 (66,67). The involvement of HIF-1 $\alpha$ in the aforementioned biological responses to catecholamine-mediated stress was also evidenced in other studies showing that the $\beta 2$ adrenergic receptor (AR)/HIF-1 $\alpha$ axis regulates angiogenesis and stress-induced pancreatic tumor growth in mouse models (68). In hypoxic melanoma cells, $\beta 3$-ARs have been found to be upregulated and involved in the increase of VEGF, as evidenced by using two $\beta 3$-AR blockers (69). Additionally, in ovarian cancer cells, the $\alpha 1$-AR blocker doxazosin prevented VEGF-mediated cell migration, proliferation, and capillary-like structure tube formation (70). These effects were dependent on the activation of VEGFR-2 and downstream signaling including HIF-1 $\alpha$ (70). Altogether, these observations may suggest that the adrenergic system plays a role in tumor angiogenesis and progression, in particular through HIF- $1 \alpha$-mediated responses and VEGF expression in hypoxic conditions. Virally encoded GPCRs may also contribute to cancer angiogenesis and progression as evidenced by the human herpesvirus-8 (HHV-8 or Kaposi's sarcoma-associated herpesvirus (KSHV))-encoded G protein-coupled receptor (vGPCR) (71). In this regard, it has been demonstrated that KSHV stimulates the expression of the angiogenic factor angiopoietin-like 4 (71) as well as the production of
VEGF through HIF-1 $\alpha$ (72). Accordingly, the expression of VGPCR in human umbilical vein endothelial cells (HUVECs) triggered cell immortalization together with a constitutive expression and activation of VEGFR-2, thus proposing a role for vGPCRs in the acquisition of the KSangiogenic phenotype in the model system used (73).

\section{GPER IS INVOLVED IN HYPOXIA-MEDIATED SIGNALING}

GPER has been recently characterized toward its ability to mediate estrogen action in reproductive, immune, skeletal, cardiovascular, and central nervous systems (5). In addition, our and other studies have largely demonstrated the involvement of GPER in the stimulatory effects elicited by estrogens in cancer cells and tumor microenvironment (6,9-11). Significantly, several studies performed in different cell and animal models have ascertained the role exerted by GPER in certain pathological conditions characterized by oxygen deficiency (30,31,74-78). In this regard, it has been demonstrated that GPER activation may decrease myocardial damage and increase functional recovery after ischemia-reperfusion (I/R) injury, which often induces dangerous complications like arrhythmia in patients with myocardial infarction (74-78). Likewise, in rat hearts of both sexes exposed to I/R injury, the activation of GPER reduced myocardial inflammation and infarct size as well as improved immunosuppression and myocardial mechanical performance (79-81). Interestingly, the expression levels of both GPER and HIF- $1 \alpha$ were found to be increased in spontaneously hypertensive rat hearts compared to normotensive controls, suggesting that HIF- $1 \alpha /$ GPER signaling may represent a transduction mediator in certain conditions characterized by elevated blood pressure (74), which is tightly linked to hypoxia (82). Of note, the selective GPER agonist G-1 markedly lowered blood pressure in normotensive and hypertensive rats $(83,84)$, thus supporting the hypothesis that GPER may be a valuable pharmacological target for the prevention/treatment of certain cardiovascular diseases. Further supporting the role elicited by GPER in hypoxic conditions, previous studies have reported that its activation may attenuate the detrimental effects induced by oxygen deficiency in some areas of the central nervous system like the hypothalamic-pituitary axis, hippocampal formation, brainstem autonomic nuclei, and spinal cord $(85,86)$. For instance, GPER activation promoted neuronal survival after global ischemia through the activation of pro-survival and anti-apoptotic signaling cascades (86). An improvement in cerebral microvascular function upon hypoxia/reoxygenation injury was also observed upon GPER activation in male and female rats (87), although sexdependent protective effects mediated by GPER have been also shown to influence the outcome of ischemic stroke (88). In this regard, it has been demonstrated that GPER expression increases after stroke in the brain of male but not female mice, thus suggesting that a gender-specific regulation of GPER may occur and influence the recovery from cerebral I/R (88). The regulation of GPER expression following hypoxia has been evaluated in breast cancer cells as well as in cancer-associated fibroblasts (CAFs) obtained from breast malignancies $(30,31)$. In these cells, hypoxia-stimulated HIF-1 $\alpha$ was found recruited to the HRE sequences located 
within the promoter region of the human GPER gene $(30,31)$. Accordingly, HIF-1 $\alpha$ was required for both the transactivation of a GPER promoter reporter gene as well as for the upregulation of GPER expression upon hypoxia $(30,31)$. These observations were further corroborated by the involvement of HIF-1 $\alpha$ /GPER signaling in VEGF expression toward tumor angiogenesis and progression $(31,89)$. In addition, HIF-1 $\alpha /$ GPER/VEGF transduction pathway was triggered in cancer cells upon exposure to copper, which showed the ability to mimic the hypoxia-mediated signaling (90). Interestingly, the copper-chelating agent TEPA exerted an inhibitory action on the activation of the aforementioned pathway (90), in accordance with previous studies demonstrating that copper-chelating agents can exert anti-tumor effects (91). Altogether, these results indicate that diverse stimuli including hypoxia may trigger relevant biological responses through GPER, which was recently shown to be also involved in the stimulatory effects exerted by aldosterone in breast cancer cells and breast tumor-derived endothelial cells (92) as well as in pregnancy-induced vasodilation of rat uterine arteries (93).

\section{GPCRS AND HYPOXIA: IMPLICATIONS FOR DRUG DISCOVERY}

The multifaceted mechanisms of oxygen sensing mainly orchestrated by HIF-1 represent an essential response to cope with hypoxic stress, which often occurs in cancer, heart disease, and stroke $(32,33)$. As many members of the GPCR family elicit a role in the intricate cell adaptation to oxygen deficiency, a cross talk between HIF-1 and GPCR-mediated pathways may be involved in the biological responses to hypoxia in the aforementioned pathological conditions. In recent years, the discovery and development of several different strategies to block HIF-1 action directly or indirectly has been suggested as a promising tool to overcome the resistance to conventional chemotherapeutic agents in hypoxic microenvironment $(34,94)$. In this vein, HIF-1 inhibitors may be regarded as golden candidates in combination treatment targeting the molecular mediators activated by hypoxia. For instance, a further approach toward new therapeutic strategies may combine the pharmacological manipulation of both HIF-1- and GPCR-mediated signaling. In addition to the therapeutic purposes, GPCRs along with HIF-1 may be regarded as further hallmarks of hypoxia signature in different pathophysiological conditions. As it concerns GPER, on the basis of its involvement in biological responses to low oxygen tension, new GPER-targeted therapies might pioneer for innovative drug discovery strategies aimed to improve the efficacy of HIF blockers and conventional angiogenic inhibitors.

\section{CONCLUSIONS}

A significant progress has been made in the past few years toward the characterization of the molecular mechanisms involved in GPCR action. In particular, many members of the GPCR family have been shown to contribute to the adaptive cell responses to low oxygen tension, which is a distinguishing feature of tumor development and certain cardiovascular diseases. In this regard, GPER may be included among the HIF-1 $\alpha$ target genes that drive cancer cell survival and malignant progression. In addition, HIF-1 $\alpha /$ GPER signaling may play a relevant role toward VEGF stimulation, angiogenesis, and cancer development. Furthermore, the role elicited by GPER in heart failure, stroke, and hypertension has been largely elucidated, paving the way for novel therapeutic approaches in these relevant illnesses that are characterized by hypoxia and ischemia.

\section{ACKNOWLEDGMENTS}

This work was supported by the Associazione Italiana per la Ricerca sul Cancro (AIRC, grant 16719/2015) and Ministero della Salute (grant 67/GR-2010-2319511). EMDF was supported by the International Cancer Research Fellowships AIRC-iCARE.

\section{REFERENCES}

1. Rosenbaum DM, Rasmussen SG, Kobilka BK. The structure and function of G-protein-coupled receptors. Nature. 2009;459:356-63.

2. Pierce KL, Premont RT, Lefkowitz RJ. Seven-transmembrane receptors. Nat Rev Mol Cell Biol. 2002;3:639-50.

3. Dorsam RT, Gutkind JS. G-protein-coupled receptors and cancer. Nat Rev Cancer. 2007;7:79-94.

4. Lappano R, Maggiolini M. G protein-coupled receptors: novel targets for drug discovery in cancer. Nat Rev Drug Discov. 2011;10:47-60.

5. Maggiolini M, Picard D. The unfolding stories of GPR30, a new membrane-bound estrogen receptor. J Endocrinol. 2010;204:10514.

6. Lappano R, Pisano A, Maggiolini M. GPER function in breast cancer: an overview. Front Endocrinol (Lausanne). 2014;5:66.

7. Albanito L, Lappano R, Madeo A, Chimento A, Prossnitz ER, Cappello AR, et al. Effects of atrazine on estrogen receptor $\alpha$ and $\mathrm{G}$ protein-coupled receptor 30-mediated signaling and proliferation in cancer cells and cancer-associated fibroblasts. Environ Health Perspect. 2015;5:493-9.

8. Maggiolini M, Vivacqua A, Fasanella G, Recchia AG, Sisci D, Pezzi V, et al. The G protein-coupled receptor GPR30 mediates c-fos up-regulation by 17 beta-estradiol and phytoestrogens in breast cancer cells. J Biol Chem. 2004;279:27008-16.

9. Pandey DP, Lappano R, Albanito L, Madeo A, Maggiolini M, Picard D. Estrogenic GPR30 signalling induces proliferation and migration of breast cancer cells through CTGF. EMBO J. 2009;28:523-32.

10. Pupo M, Pisano A, Lappano R, Santolla MF, De Francesco EM, Abonante $\mathrm{S}$, et al. Bisphenol A induces gene expression changes and proliferative effects through GPER in breast cancer cells and cancer-associated fibroblasts. Environ Health Perspect. 2012;120:1177-82.

11. Madeo A, Maggiolini M. Nuclear alternate estrogen receptor GPR30 mediates 17beta-estradiol-induced gene expression and migration in breast cancer-associated fibroblasts. Cancer Res. 2010;70:6036-46.

12. Lappano R, Rosano C, De Marco P, De Francesco EM, Pezzi V, Maggiolini M. Estriol acts as a GPR30 antagonist in estrogen receptor-negative breast cancer cells. Mol Cell Endocrinol. 2010;320:162-70.

13. Ariazi EA, Brailoiu E, Yerrum S, Shupp HA, Slifker MJ, Cunliffe HE, et al. The $\mathrm{G}$ protein-coupled receptor GPR30 inhibits proliferation of estrogen receptor-positive breast cancer cells. Cancer Res. 2010;70:1184-94.

14. Wei W, Chen ZJ, Zhang KS, Yang XL, Wu YM, Chen XH, et al. The activation of $\mathrm{G}$ protein-coupled receptor 30 (GPR30) inhibits proliferation of estrogen receptor-negative breast cancer cells in vitro and in vivo. Cell Death Dis. 2014;5, e1428. 
15. Weißenborn $\mathrm{C}$, Ignatov $\mathrm{T}$, Ochel $\mathrm{HJ}$, Costa $\mathrm{SD}$, Zenclussen $\mathrm{AC}$, Ignatova $\mathrm{Z}$, et al. GPER functions as a tumor suppressor in triple-negative breast cancer cells. J Cancer Res Clin Oncol. 2014;140:713-23.

16. Weißenborn $\mathrm{C}$, Ignatov $\mathrm{T}$, Poehlmann A, Wege AK, Costa SD, Zenclussen AC, et al. GPER functions as a tumor suppressor in MCF-7 and SK-BR-3 breast cancer cells. J Cancer Res Clin Oncol. 2014;140:663-71.

17. Marjon NA, Hu C, Hathaway HJ, Prossnitz ER. G proteincoupled estrogen receptor regulates mammary tumorigenesis and metastasis. Mol Cancer Res. 2014;12:1644-54.

18. Arias-Pulido H, Royce M, Gong Y, Joste N, Lomo L, Lee SJ, et al. GPR30 and estrogen receptor expression: new insights into hormone dependence of inflammatory breast cancer. Breast Cancer Res Treat. 2010;123:51-8.

19. Ignatov T, Weißenborn C, Poehlmann A, Lemke A, Semczuk A, Roessner A, et al. GPER-1 expression decreases during breast cancer tumorigenesis. Cancer Invest. 2013;31:309-15.

20. Ignatov A, Ignatov T, Weissenborn C, Eggemann H, Bischoff J, Semczuk A, et al. G-protein-coupled estrogen receptor GPR30 and tamoxifen resistance in breast cancer. Breast Cancer Res Treat. 2011;128:457-66.

21. Sjöström M, Hartman L, Grabau D, Fornander T, Malmström P, Nordenskjöld B, et al. Lack of $\mathrm{G}$ protein-coupled estrogen receptor (GPER) in the plasma membrane is associated with excellent long-term prognosis in breast cancer. Breast Cancer Res Treat. 2014;145:61-71.

22. Smith HO, Leslie KK, Singh M, Qualls CR, Revankar CM, Joste NE, et al. GPR30: a novel indicator of poor survival for endometrial carcinoma. Am J Obstet Gynecol. 2007;196:386. e1-11.

23. Smith HO, Arias-Pulido H, Kuo DY, Howard T, Qualls CR, Lee SJ, et al. GPR30 predicts poor survival for ovarian cancer. Gynecol Oncol. 2009;114:465-71.

24. Filardo EJ, Graeber CT, Quinn JA, Resnick MB, Giri D, DeLellis RA, et al. Distribution of GPR30, a seven membranespanning estrogen receptor, in primary breast cancer and its association with clinicopathologic determinants of tumor progression. Clin Cancer Res. 2006;12:6359-66.

25. Albanito L, Sisci D, Aquila S, Brunelli E, Vivacqua A, Madeo A, et al. Epidermal growth factor induces $\mathrm{G}$ protein-coupled receptor 30 expression in estrogen receptor-negative breast cancer cells. Endocrinology. 2008;149:3799-808.

26. Vivacqua A, Lappano R, De Marco P, Sisci D, Aquila S, De Amicis $\mathrm{F}$, et al. G protein-coupled receptor 30 expression is upregulated by EGF and TGF alpha in estrogen receptor alphapositive cancer cells. Mol Endocrinol. 2009;23:1815-26.

27. Bartella V, De Marco P, Malaguarnera R, Belfiore A, Maggiolini M. New advances on the functional cross-talk between insulinlike growth factor-I and estrogen signalling in cancer. Cell Signal. 2012;24:1515-21.

28. De Marco P, Bartella V, Vivacqua A, Lappano R, Santolla MF, Morcavallo A, et al. Insulin-like growth factor-I regulates GPER expression and function in cancer cells. Oncogene. 2013;32:67888.

29. De Marco P, Romeo E, Vivacqua A, Malaguarnera R, Abonante $\mathrm{S}$, Romeo $\mathrm{F}$, et al. GPER1 is regulated by insulin in cancer cells and cancer-associated fibroblasts. Endocr Relat Cancer. 2014;21:739-53.

30. Recchia AG, De Francesco EM, Vivacqua A, Sisci D, Panno $\mathrm{ML}$, Andò S, et al. The G protein-coupled receptor 30 is upregulated by hypoxia-inducible factor-1alpha (HIF-1alpha) in breast cancer cells and cardiomyocytes. J Biol Chem. 2011:286:10773-82.

31. De Francesco EM, Lappano R, Santolla MF, Marsico S, Caruso A, Maggiolini M. HIF-1 $\alpha$ /GPER signaling mediates the expression of VEGF induced by hypoxia in breast cancer associated fibroblasts (CAFs). Breast Cancer Res. 2013;15:R64.

32. Harris AL. Hypoxia-a key regulator factor in tumor growth. Nat Rev Cancer. 2002;2:38-47.

33. Bishop T, Ratcliffe PJ. HIF hydroxylase pathways in cardiovascular physiology and medicine. Circ Res. 2015;117:65-79.

34. Semenza GL. Hypoxia-inducible factors: mediators of cancer progression and targets for cancer therapy. Trends Pharmacol Sci. 2012;33:207-14.
35. Manalo DJ, Rowan A, Lavoie T, Natarajan L, Kelly BD, Ye SQ, et al. Transcriptional regulation of vascular endothelial cell responses to hypoxia by HIF-1. Blood. 2005;105:659-69.

36. Glück AA, Aebersold DM, Zimmer Y, Medová M. Interplay between receptor tyrosine kinases and hypoxia signaling in cancer. Int J Biochem Cell Biol. 2015;62:101-14.

37. Wang GL, Semenza GL. General involvement of hypoxiainducible factor 1 in transcriptional response to hypoxia. Proc Natl Acad Sci U S A. 1993;90:4304-8.

38. Semenza GL, Aganì F, Booth G, Forsythe J, Iyer N, Jiang H, et al. Structural and functional analysis of hypoxia-inducible factor I. Kidney Int. 1997;51:553-5.

39. Guo M, Cai C, Zhao G, Qiu X, Zhao H, Ma Q, et al. Hypoxia promotes migration and induces CXCR4 expression via HIF$1 \alpha$ activation in human osteosarcoma. PLoS One. 2014;9, e90518.

40. Kimura M, Mizukami Y, Miura T, Fujimoto K, Kobayashi S, Matsuzaki M. Orphan G protein-coupled receptor, GPR41, induces apoptosis via a p53/Bax pathway during ischemic hypoxia and reoxygenation. J Biol Chem. 2001;276:26453-60.

41. Adams JW, Wang J, Davis JR, Liaw C, Gaidarov I, Gatlin J, et al. Myocardial expression, signaling, and function of GPR22: a protective role for an orphan $\mathrm{G}$ protein-coupled receptor. Am J Physiol Heart Circ Physiol. 2008;295:H509-21.

42. Corbi G, Conti V, Russomanno G, Longobardi G, Furgi G, Filippelli A, et al. Adrenergic signaling and oxidative stress: a role for sirtuins? Front Physiol. 2013;4:324.

43. Jordan BA, Gomes I, Rios C, Filipovska J, Devi LA. Functional interactions between mu opioid and alpha 2A-adrenergic receptors. Mol Pharmacol. 2003;64:1317-24.

44. Headrick JP, See Hoe LE, Du Toit EF, Peart JN. Opioid receptors and cardioprotection-opioidergic conditioning' of the heart. Br J Pharmacol. 2015;172:2026-50.

45. Gao CJ, Niu L, Ren PC, Wang W, Zhu C, Li YQ, et al. Hypoxic preconditioning attenuates global cerebral ischemic injury following asphyxial cardiac arrest through regulation of delta opioid receptor system. Neuroscience. 2012;202:352-62.

46. Caprara V, Scappa S, Garrafa E, Di Castro V, Rosanò L, Bagnato A, et al. Endothelin-1 regulates hypoxia-inducible factor- $1 \alpha$ and $-2 \alpha$ stability through prolyl hydroxylase domain 2 inhibition in human lymphatic endothelial cells. Life Sci. 2014;118:185-90.

47. Hu HT, Ma QY, Zhang D, Shen SG, Han L, Ma YD, et al. HIF1alpha links beta-adrenoceptor agonists and pancreatic cancer cells under normoxic condition. Acta Pharmacol Sin. 2010;31:102-10.

48. Lee SJ, No YR, Dang DT, Dang LH, Yang VW, Shim H, et al. Regulation of hypoxia-inducible factor $1 \alpha$ (HIF-1 $\alpha)$ by lysophosphatidic acid is dependent on interplay between p53 and Krüppel-like factor 5. J Biol Chem. 2013;288:25244-53.

49. Baeriswyl V, Christofori G. The angiogenic switch in carcinogenesis. Semin Cancer Biol. 2009;19:329-37.

50. Ferrara N, Gerber HP, LeCouter J. The biology of VEGF and its receptors. Nat Med. 2003;9:66-76.

51. Richard DE, Vouret-Craviari V, Pouyssegur J. Angiogenesis and G-protein-coupled receptors: signals that bridge the gap. Oncogene. 2001;20:1556-62.

52. Sumida H, Noguchi K, Kihara Y, Abe M, Yanagida K, Hamano $\mathrm{F}$, et al. LPA4 regulates blood and lymphatic vessel formation during mouse embryogenesis. Blood. 2010;116:5060-70.

53. Moore BB, Keane MP, Addison CL, Arenberg DA, Strieter RM. CXC chemokine modulation of angiogenesis: the importance of balance between angiogenic and angiostatic members of the family. J Investig Med. 1998;46:113-20.

54. Liu Y, Wada R, Yamashita T, Mi Y, Deng CX, Hobson JP, et al. Edg-1, the G protein-coupled receptor for sphingosine-1-phosphate, is essential for vascular maturation. J Clin Invest. 2000;106:951-61.

55. Zeng $\mathrm{H}$, Zhao D, Yang S, Datta K, Mukhopadhyay D. Heterotrimeric $\mathrm{G} \alpha \mathrm{q} / \mathrm{G} \alpha 11$ proteins function upstream of vascular endothelial growth factor (VEGF) receptor-2 (KDR) phosphorylation in vascular permeability factor/VEGF signaling. $\mathrm{J}$ Biol Chem. 2003;278:20738-45.

56. Rivas V, Carmona R, Muñoz-Chápuli R, Mendiola M, Nogués L, Reglero $\mathrm{C}$, et al. Developmental and tumoral vascularization is 
regulated by $\mathrm{G}$ protein-coupled receptor kinase 2. P J Clin Invest. 2013;123:4714-30.

57. Sarvaiya PJ, Guo D, Ulasov I, Gabikian P, Lesniak MS. Chemokines in tumor progression and metastasis. Oncotarget. 2013;4:2171-85.

58. Guha S, Eibl G, Kisfalvi K, Fan RS, Burdick M, Reber H, et al. Broad-spectrum $G$ protein-coupled receptor antagonist, [DArg1, D-Trp5,7,9, Leu11]SP: a dual inhibitor of growth and angiogenesis in pancreatic cancer. Cancer Res. 2005;65:2738-45.

59. Jin F, Brockmeier U, Otterbach F, Metzen E. New insight into the SDF-1/CXCR4 axis in a breast carcinoma model: hypoxiainduced endothelial SDF-1 and tumor cell CXCR4 are required for tumor cell intravasation. Mol Cancer Res. 2012;10:1021-31.

60. Nikitenko LL, Leek R, Henderson S, Pillay N, Turley H, Generali D, et al. The G-protein-coupled receptor CRLR is upregulated in an autocrine loop with adrenomedullin in clear cell renal cell carcinoma and associated with poor prognosis. Clin Cancer Res. 2013;19:5740-8.

61. Nikitenko LL, Smith DM, Bicknell R, Rees MC. Transcriptional regulation of the CRLR gene in human microvascular endothelial cells by hypoxia. FASEB J. 2003;17:1499-501.

62. Yamashita K, Discher DJ, Hu J, Bishopric NH, Webster KA Molecular regulation of the endothelin-1 gene by hypoxia. Contributions of hypoxia-inducible factor-1, activator protein-1, GATA-2, AND p300/CBP. J Biol Chem. 2001;276:12645-53.

63. Wu MH, Huang CY, Lin JA, Wang SW, Peng CY, Cheng HC, et al. Endothelin-1 promotes vascular endothelial growth factordependent angiogenesis in human chondrosarcoma cells. Oncogene. 2014;33:1725-35.

64. Spinella F, Rosanò L, Di Castro V, Natali PG, Bagnato A. Endothelin-1 induces vascular endothelial growth factor by increasing hypoxia-inducible factor-1alpha in ovarian carcinoma cells. J Biol Chem. 2002;277:27850-5.

65. Bartella V, De Francesco EM, Perri MG, Curcio R, Dolce V, Maggiolini M, et al. The G protein estrogen receptor (GPER) is regulated by endothelin-1 mediated signaling in cancer cells. Cell Signal. 2016;2:61-71.

66. Moretti S, Massi D, Farini V, Baroni G, Parri M, Innocenti S, et al. $\beta$-Adrenoceptors are upregulated in human melanoma and their activation releases pro-tumorigenic cytokines and metalloproteases in melanoma cell lines. Lab Invest. 2013;279.

67. Yang EV, Kim SJ, Donovan EL, Chen M, Gross AC, Webster Marketon JI, et al. Norepinephrine upregulates VEGF, IL-8, and IL-6 expression in human melanoma tumor cell lines: implications for stress-related enhancement of tumor progression. Brain Behav Immun. 2009:23:267-75.

68. Shan T, Ma J, Ma Q, Guo K, Guo J, Li X, et al. $\beta 2$-AR-HIF-1 $\alpha$ : a novel regulatory axis for stress-induced pancreatic tumor growth and angiogenesis. Curr Mol Med. 2013;13:1023-34.

69. Dal Monte M, Casini G, Filippi L, Nicchia GP, Svelto M, Bagnoli P. Functional involvement of $\beta 3$-adrenergic receptors in melanoma growth and vascularization. J Mol Med (Berl). 2013;91:1407-19.

70. Park MS, Kim BR, Dong SM, Lee SH, Kim DY, Rho SB The antihypertension drug doxazosin inhibits tumor growth and angiogenesis by decreasing VEGFR-2/Akt/mTOR signaling and VEGF and HIF-1 $\alpha$ expression. Oncotarget. 2014;5:4935-44.

71. Ma T, Jham BC, Hu J, Friedman ER, Basile JR, Molinolo A, et $a l$. Viral G protein-coupled receptor up-regulates angiopoietinlike 4 promoting angiogenesis and vascular permeability in Kaposi's sarcoma. Proc Natl Acad Sci U S A. 2010;107:14363-8.

72. Sodhi A, Montaner S, Patel V, Zohar M, Bais C, Mesri EA, et al. The Kaposi's sarcoma-associated herpes virus $G$ protein-coupled receptor up-regulates vascular endothelial growth factor expression and secretion through mitogen-activated protein kinase and p38 pathways acting on hypoxia-inducible factor 1alpha. Cancer Res. 2000;60:4873-80.

73. Bais C, Van Geelen A, Eroles P, Mutlu A, Chiozzini C, Dias S, et al. Kaposi's sarcoma associated herpesvirus G protein-coupled receptor immortalizes human endothelial cells by activation of the VEGF receptor-2/ KDR. Cancer Cell. 2003;3:131-43.
74. De Francesco EM, Angelone T, Pasqua T, Pupo M, Cerra MC, Maggiolini M. GPER mediates cardiotropic effects in spontaneously hypertensive rat hearts. PLoS One. 2013;8, e69322.

75. Patel VH, Chen J, Ramanjaneya M, Karteris E, Zachariades E, Thomas P, et al. G-protein coupled estrogen receptor 1 expression in rat and human heart: protective role during ischaemic stress. Int J Mol Med. 2010;26:193-9.

76. Meyer MR, Prossnitz ER, Barton M. The G protein-coupled estrogen receptor GPER/GPR30 as a regulator of cardiovascular function. Vascul Pharmacol. 2011;55:17-25.

77. Deschamps AM, Murphy E, Sun J. Estrogen receptor activation and cardioprotection in ischemia reperfusion injury. Trends Cardiovasc Med. 2011;20:73-8.

78. Deschamps AM, Murphy E. Activation of a novel estrogen receptor, GPER, is cardioprotective in male and female rats. Am J Physiol Heart Circ Physiol. 2009;297:H1806-13.

79. Weil BR, Manukyan MC, Herrmann JL, Wang Y, Abarbanell AM, Poynter JA, et al. Signaling via GPR30 protects the myocardium from ischemia/reperfusion injury. Surgery. 2010;148:436-43.

80. Zhang B, Subramanian S, Dziennis S, Jia J, Uchida M, Akiyoshi $\mathrm{K}$, et al. Estradiol and G1 reduce infarct size and improve immunosuppression after experimental stroke. J Immunol. 2010;18:4087-94.

81. Li WL, Xiang W, Ping Y. Activation of novel estrogen receptor GPER results in inhibition of cardiocyte apoptosis and cardioprotection. Mol Med Rep. 2015;12:2425-30.

82. Czibik G. Complex role of the HIF system in cardiovascular biology. J Mol Med (Berl). 2010;88:1101-1.

83. Lindsey SH, Cohen JA, Brosnihan KB, Gallagher PE, Chappell MC. Chronic treatment with the $G$ protein-coupled receptor 30 agonist G-1 decreases blood pressure in ovariectomized mRen2.Lewis rats. Endocrinology. 2009;150:3753-8.

84. Meyer MR, Prossnitz ER, Barton M. GPER/GPR30 and regulation of vascular tone and blood pressure. Immunol, Endocr Metab Agents Med Chem. 2011;11:255-61.

85. Brailoiu E, Dun SL, Brailoiu GC, Mizuo K, Sklar LA, Oprea TI, et al. Distribution and characterization of estrogen receptor $\mathrm{G}$ protein-coupled receptor 30 in the rat central nervous system. J Endocrinol. 2007;193:311-21.

86. Chen J, Hu R, Ge H, Duanmu W, Li Y, Xue X, et al. G-proteincoupled receptor 30-mediated antiapoptotic effect of estrogen on spinal motor neurons following injury and its underlying mechanisms. Mol Med Rep. 2015;12:1733-40.

87. Murata T, Dietrich HH, Xiang C, Dacey Jr RG. G proteincoupled estrogen receptor agonist improves cerebral microvascular function after hypoxia/reoxygenation injury in male and female rats. Stroke. 2013;44:779-85.

88. Broughton BR, Brait VH, Guida E, Lee S, Arumugam TV, Gardiner-Mann CV, et al. Stroke increases G protein-coupled estrogen receptor expression in the brain of male but not female mice. Neurosignals. 2013;21:229-39.

89. De Francesco EM, Pellegrino M, Santolla MF, Lappano R, Ricchio E, Abonante S, et al. GPER mediates activation of HIF1 $\alpha /$ VEGF signaling by estrogens. Cancer Res. 2014;74:4053-64.

90. Rigiracciolo DC, Scarpelli A, Lappano R, Pisano A, Santolla MF, De Marco P, et al. Copper activates HIF-1 $\alpha /$ GPER/VEGF signalling in cancer cells. Oncotarget. 2015;33:34158-77.

91. Brewer GJ. Anticopper therapy against cancer and diseases of inflammation and fibrosis. Drug Discov Today. 2005;10:1103-19.

92. Rigiracciolo DC, Scarpelli A, Lappano R, Pisano A, Santolla MF, Avino S, et al. GPER is involved in the stimulatory effects of aldosterone in breast cancer cells and breast tumor-derived endothelial cells. Oncotarget. 2015 Dec 5. doi: 10.18632/ oncotarget.6475.

93. Tropea T, De Francesco EM, Rigiracciolo D, Maggiolini M, Wareing $\mathrm{M}$, Osol $\mathrm{G}$, et al. Pregnancy augments $\mathrm{G}$ protein estrogen receptor (GPER) induced vasodilation in rat uterine arteries via the nitric oxide-cGMP signaling pathway. PLoS One. 2015;10(11), e0141997.

94. Xia Y, Choi HK, Lee K. Recent advances in hypoxia-inducible factor (HIF)-1 inhibitors. Eur J Med Chem. 2012;49:24-40. 